EGU21-15085

https://doi.org/10.5194/egusphere-egu21-15085

EGU General Assembly 2021

(c) Author(s) 2021. This work is distributed under

the Creative Commons Attribution 4.0 License.

\title{
Thermo-mechanical modelling of subducting plate delamination in the northern Apennines
}

\author{
Ana M. Negredo ${ }^{1,2}$, Carlos Clemente ${ }^{1}$, Eugenio Carminati ${ }^{3}$, Ivone Jiménez-Munt ${ }^{4}$, Jaume Vergés ${ }^{4}$, \\ Javier Fullea ${ }^{1}$, and Montserrat Torné ${ }^{4}$ \\ ${ }^{1}$ Department of Physics of the Earth and Astrophysics, Complutense University of Madrid, Madrid, Spain \\ (amnegred@ucm.es) \\ ${ }^{2}$ Institute of Geosciences IGEO, UCMDCSIC, Madrid, Spain \\ ${ }^{3}$ Department of Earth Sciences, Università degli studi di Roma La Sapienza, Rome, Italy \\ ${ }^{4}$ Group of Dynamics of the Lithosphere, Geosciences Barcelona (Geo3Bcn[CSIC), Barcelona, Spain
}

\begin{abstract}
A number or previous studies indicate the possibility of post-collisional continental delamination in the northern Apennines. In this study we investigate by means of thermo-mechanical modelling the conditions for, and consequences of, delamination postdating continental subduction in this region. The modelled cross-section strikes approximately from Corsica to the Adriatic Sea. The initial model setup simulates the scenario at ca $20 \mathrm{Ma}$, where the oceanic lithosphere of the westward-subducting Adria plate was entirely consumed and some amount of continental subduction also occurred. The negative buoyancy of the slab remnant, together with the low viscosity of the dragged down lower continental crust, promote lithospheric mantle sinking into the mantle and asthenospheric upwelling and its lateral expansion along the lower crust. Consistent with geological data, the compressional front produced by delamination migrates about $260 \mathrm{~km}$ eastwards, causing a similar migrating pattern of extension from the northern Tyrrhenian Sea, to Tuscany and the seismogenically active Apennines backbone. The topographic response is computed by means of a true free-surface approach, and reflects the same eastward migrating pattern of uplift caused by asthenospheric inflow in the internal part of the system and crustal thickening; and subsidence at the front caused by the negative buoyancy of the sinking Adria slab. The conditions for the occurrence of magmatism and high heat flow beneath Tuscany are also explored. Simulations resulting in fast migration of the delamination front predict slab necking and breakoff, which could be consistent with the slab window observed beneath the central Apennines. Subcrustal seismicity beneath the Northern Apennines can be interpreted as the result to this incipient slab necking. This is a GeoCAM contribution (PGC2018-095154-B-I00)
\end{abstract}

